\title{
QUAL O LUGAR DAS EMOÇÕES NOS ESTUDOS DA LINGUAGEM DO SÉCULO XXI?
}

\section{WHAT THE REAL PLACE OF EMOTIONS IN THE LANGUAGE STUDIES OF THE XXI CENTURY?}

\author{
Marinalva Vieira Barbosa ${ }^{1}$
}

RESUMO: Este artigo apresenta uma reflexão sobre a relação entre linguagem, emoção e enunciação. Para realizar o estudo, tomo como base discursos de professores e alunos em situação de interação em sala de aula. Tendo como ancoragem teórica as concepções bakhtinianas, analiso as dimensões lingüísticas e discursivas desses discursos. O discurso constituído e constitutivo de emoção é signo do que pode ocorrer ao sujeito que, pondo-se no interior de uma situação de interação, enuncia um estado afetivo em face do diálogo com a alteridade (CHARAUDEAU, 2000).

ABSTRACT: This article presents a reflection about relationship among language, emotion and enunciation. In order to conduct this study, both teachers and students' discourses during classroom interactions will be analyzed. Adopting Bakhtin's conceptions as the theoretical basis, I analyze either linguistic or discursive dimensions of such discourses. A discourse that is constituted and constitutive of emotion is a sign of what may occur to the subject who, from within an interaction situation, enunciates an affective state while facing the dialogue with otherness (CHARAUDEAU, 2000).

Palavras-Chave: Linguagem; emoção; enunciação.

Key-word: Language; emotion; enunciation.

\footnotetext{
${ }^{1}$ Universidade Federal do Triângulo Mineiro - UFTM. Uberaba/MG. Doutor em Lingüística. Professor Adjunto. marinalvav@gmail.com
} 


\section{INTRODUÇÃO}

A problemática de como tratar o as emoções na linguagem, tal como aparece nas interações entre sujeitos, não é nova. Trata-se de um tema caro aos estudos psicológicos e filosóficos e que possui pouca relevância para os estudos lingüísticos e discursivos. Esse estatuto marginal põe de imediato o problema de saber em que se apoiar teoricamente para construir as análises, pois ainda não são comuns teorias de discurso que apresentem bases consistentes de como focalizar os processos de inscrição das afetividades na linguagem. Estudos como os desenvolvidos por Plantin (2003), visando construir formas de abordagens da emoção falada e da fala emocionada, e os de Charaudeau (2000) com o objetivo de responder se as emoções podem ser objeto de interesse dos estudos do discurso, demonstram que a abordagem discursiva do tema ainda exige construções tanto do objeto como do campo teórico e metodológico de sustentação. Nos estudos da linguagem, ainda existem dificuldades para estabelecer diferenciação entre "a expressão de emoção (as marcas de afetividade na linguagem) e os patêmicos ou os elementos suscetíveis de provocar emoção no alocutário 2" (AMOSSY, 2006, p. 197).

Parte dessa dificuldade resulta do fato de que a lingüística moderna dispensou pouca atenção à questão das emoções. A concepção de língua como sistema (central a fundação dessa ciência) assumiu posição hegemônica e

\footnotetext{
2 "l'expression de l'émotion (les marques de l'affectivité dans le langage) et les pathémes ou
} éléments susceptibles de créer l'émotion chez l'allocutaire". 
desencorajou qualquer interesse pelo tema. A concepção de sistema, este constituído por formas fonéticas, gramaticais e lexicais, visava responder a um ideal de cientificidade e, por isso, culmina na defesa da língua como objeto universal e racional. A plena aceitação da língua e a rejeição da fala, o que significa o privilegio do cálculo e deixou pouco espaço para tratar de algo que não se ajustava a beleza das linguagens naturais. Bakhtin (1929), na crítica que elabora aos fundamentos da Lingüística, afirma que a língua como sistema dispensa todo ato de criação vindo dos sujeitos. A este é imposto normas fixas que devem tão-somente ser aceitas. Ou seja, a língua sobrepõe-se ao sujeito, o que é um traço próprio do racionalismo.

É a eventicidade das emoções que se transforma no maior obstáculo, pois resulta de associações que não interessam às ciências lingüísticas porque, sendo o homem um animal racional, sua língua não deve apresentar vestígios emocionais. A posição de Sapir (1921) a esse respeito é radical: o elemento emotivo deve ser excluído porque ameaça a pureza e clareza de funcionamento da língua. É importante prever, nesse caso, um falante que retenha parte do sistema, mas que não intervenha nele com elementos advindos das instâncias subjetivas. Há aqui a reafirmação da visão, vinda dos gramáticos tradicionais, que toma o afetivo como sinônimo de ilogicidade e que, no domínio da língua, passa a ser traduzido como agramaticidade. Os lingüistas modernos, embora fundem suas bases teóricas na oposição aos estudos gramaticais, não questionam ou refutam a dupla negação.

Entretanto, em alguns momentos, houve tentativas de pensar a linguagem fora das oposições criadas por Saussure (1919). As relações entre linguagem e emoção foram objetos de discussão no âmbito da Estilística. É o que podemos encontrar, por exemplo, nas concepções defendidas por Bally, no livro Le langage et la vie (1913), faz uma síntese expositiva de sua posição quanto à relação linguagem e emoção, afirmando que: a) uma língua natural é a expressão da vida social e individual; b) e a vida pode ser caracterizada pela importância que exercem os elementos afetivos; e c) e, portanto, os elementos que marcam a presença da vida na língua exercem um papel importante a compreensão desse objeto. Por isso defende que a Lingüística deve se interessar pelos elementos afetivos, visto que seu objetivo é pôr em evidência a verdadeira natureza da língua. $\mathrm{O}$ autor vai mais longe quando afirma que tal atenção deve ser dada porque o objetivo dessa ciência não pode se reduzir à construção de silogismos, abstrações, definição de períodos ou então se curvar às leis filosóficas ancestrais, mas, sim, o de se pôr a serviço da vida, o que implica no compromisso de observar todas as suas formas de manifestação. 
Bally, ao se deter nos sentidos afetivos, num primeiro momento, confronta-se com a concepção que reduz a língua a uma construção puramente abstrata. Seu posicionamento criava uma espécie de problema insolúvel para a Lingüística que se buscava fundar, pois trazer as emoções para o campo da língua implicava promover rupturas importantes nas bases dicotômicas propostas por Saussure. E como Saussure, Bally também assume o pressuposto de que o signo lingüístico tem duas propriedades legítimas: a arbitrariedade e a linearidade. Inscrever o afetivo na língua implica na admissão de que, mesmo o signo lingüístico, pode ser outro quando posto em uso pelo falante.

A solução encontrada é então pôr o afetivo sob os cuidados da estilística, estabelecendo, com isso, uma outra divisão: entre atos da língua e atos afetivos. Estes últimos entendidos como aqueles que escapavam às normas do sistema. Os fatos de ordem afetiva eram vistos como algo circunscrito ao individual, ao singularizado. Bally jogou para a estilística a responsabilidade de cuidar daquilo que, por ser ligado ao falante, não tem existência estável nas estruturas da língua. É o estudo de elementos não lingüísticos que interfere no lingüístico. Em termos de estudos, as emoções passam então a ser a forma estilizada de exploração de um traço fônico, o emprego de determinados itens lexicais.

Uma outra tentativa de reconhecimento da presença das emoções na língua talvez possa ser vinculada às reflexões de Roman Jakobson. Ancorado na concepção de linguagem em ação, Jakobson estudou a língua com o objetivo de desvendar a estrutura do ato comunicativo. Para tanto, buscou definir as funções do ato comunicativo partindo do pressuposto de que uma estrutura pode ser classificada como um mecanismo de relações determinado pelas suas funções. Na perspectiva de Jakobson, qualquer mecanismo, seja a linguagem ou a máquina, apresenta uma função, o que explica a pergunta direcionadora dos seus estudos: qual é a função da linguagem? A comunicação. Sendo esta o objetivo central, os sujeitos que falam são então movidos pelo desejo de descobrir qual a finalidade das palavras, sentenças e enunciados. A linguagem é um conjunto de meios que serve para um fim particular, a comunicação entre falantes. Diante dessa visão esquemática, o autor analisa quais funções constituem a comunicação pela linguagem baseado na visão de que o processo de comunicação entre falantes é dual porque se divide em emissor e o receptor. Para uma dessas orientações, o autor aponta: 
A função dita "expressiva" ou emotiva, centrada sobre o destinador, visa a uma expressão direta da atitude do sujeito em relação àquilo de que ele fala. Essa atitude tende a dar a impressão de uma certa emoção, verdadeira ou dissimulada. [...]. A camada puramente emotiva, na língua, é representada pelas interjeições [...]. A função emotiva, evidente nas interjeições, colore, em algum grau, todos os nossos propósitos, no nível fônico, gramatical e lexical (JAKOBSON, 1963, pp.122-123).

A função dita emotiva é definida como a parte da comunicação que, por estar direcionada para o destinatário, visa promover a expressão direta da atitude do sujeito a respeito do objeto falado. $\mathrm{O}$ autor assinala a existência de ordem hierárquica entre as funções (denotativa, conativa, poética, fática e emotiva) e a partir disso defende que, embora a função denotativa seja dominante, "a participação adicional de outras funções em tais mensagens deve ser levada em conta pelo lingüista atento". Tal posição não se descola da visão majoritária de que o afetivo é o acessório, tanto que Jakobson conclui: "devemos evidentemente concordar com Sapir em que, no conjunto, 'a ideação reina, suprema, na linguagem.(...)'; todavia, a supremacia não autoriza os lingüistas a negligenciarem os 'fatores secundários"' (JAKOBSON, 1963, pp.122-123). Existe a palavra cujos sentidos são destituídos de acentos avaliativos, porque constituída pelo puro ato de cognição, de inteligência. A palavra denotada, passada para o interlocutor em forma de mensagem limpa, clara, corresponde à palavra não marcada por esse sentido acessório.

Jakobson, como Bally, admite a existência de elementos afetivos na língua, mas os põe na oposição aos atos intelectuais. De certa forma, a função emotiva é aquela que vai trazer um colorido aos propósitos do falante, sendo que estes são apresentados pelas demais funções. Há aqui a admissão do emotivo, mas o seu estatuto é secundário, daí que surge sua precisa localização: "O extrato puramente emotivo da linguagem é apresentado pelas interjeições" (idem). São formas da língua que diferem daquelas que aparecem para formar a linguagem denotativa. A diferença surge porque a função emotiva apresenta configurações "sonoras peculiares e incomuns". O autor reconhece a presença do afetivo na língua, mas o põe na categoria dos elementos secundários, o que reafirma o signo emotivo como pertencente somente ao domínio do que é individual e pertencente ao lado não sistematizável da língua.

Ao contrário do que diz Bakhtin (1929), na perspectiva de Jakobson o signo lingüístico, na sua função majoritária (a denotativa), é uma unidade material e discreta cujo funcionamento se constrói numa realidade 
independente e à parte do sujeito que o usa. Como não tem um lugar central na língua, nada mais adequado do que pôr o emotivo no domínio das interjeições. O autor não só localiza um lugar preciso, mas faz disso o resultado de uma experiência íntima que vem à tona numa fala autocentrada e regida pela cognição. Isto porque, na sua concepção, as interjeições afastam-se dos procedimentos orientadores da linguagem referencial. Em suma, Jakobson admite a presença das emoções no campo lingüístico, mas desde que elas fiquem delimitadas em lugares específicos que garantam a continuidade do aspecto asséptico da língua.

Dando um salto no tempo e vindo para o cenário dos estudos lingüísticos contemporâneos, Kerbrat-Orecchioni (2000) considera que as abordagens contemporâneas situam-se principalmente em uma perspectiva interacionista: isso teria implicado na valorização dos elementos comunicativos e menos dos expressivos. Houve mudança de perspectiva, segundo a autora, porque as abordagens tradicionais sempre estiveram centradas na oposição entre componentes comunicativos e expressivos, enquanto que as atuais caminharam para discutir as emoções como elemento comunicativo. Olhando o cenário dos estudos lingüísticos, de modo geral, é inegável que houve certo renascimento do interesse pela discussão a respeito das formas de inscrição das emoções na linguagem. Entretanto, esse movimento não vem ocorrendo de forma simples e tranqüila porque não é simplesmente dizer que, a partir de agora, vamos considerar a existência da relação língua e emoção. Não é só acrescê-la ao que já está estabelecido. Como a exclusão não foi gratuita, a inclusão implica questionar muitas das concepções sobre língua, linguagem, discurso. Implica perder a desconfiança nas instabilidades e, inclusive, nos repormos como sujeitos produtores de conhecimentos, $\mathrm{o}$ que ainda se constitui ponto de grande resistência.

Os estudos atuais acerca do tema continuam fortemente influenciados pelo paradigma racional. Os posicionamentos assumidos pelos lingüistas "fundadores", nas mais variadas formas, ainda emergem nas discussões contemporâneas. No cenário dos estudos lingüísticos franceses, por exemplo, predominam os estudos de cunho gramatical e lexical. Trabalha-se com afinco para construir uma gramática das emoções baseada nas gramáticas tradicionais (definir adjetivos, verbos e substantivos de emoção) ou então nas concepções da gramática gerativa. A esperança não manifesta é a de que com a definição gramatical se possa chegar a um quadro indicador da estruturação das emoções como ação humana. As vertentes gramaticais, sabemos, têm suas bases fincadas nas concepções que tomam a língua como um objeto abstrato. 
As abordagens lexicais, morfossintáticas e semânticas são referências constantes para os estudos das afetividades na linguagem porque propõem estruturar o léxico e a sintaxe relacionados a esse fenômeno. Não raro, as abordagens discursivas e argumentativas recorrem a definições puramente lingüísticas para construir a estrutura discursiva das emoções. Porém, no que concerne ao aspecto lingüísticos desse fenômeno, há muita divergência no que se refere a metodologia e, sobretudo, quanto aos resultados que os estudos chegam sobre o que seria a estrutura lingüística das emoções. Apegadas às discussões clássicas desenvolvidas pela filosofia e pela psicologia, encontram dificuldades para definir como as emoções podem ser circunscritas nos domínios lingüísticos. Prevalecem, ainda que indiretamente, as concepções de que o componente afetivo pode ser tratado como universal e/ou como parte facultativa ou adicional à linguagem. Conseqüentemente, hoje ainda não existe um quadro teórico que ofereça explicações satisfatórias a respeito dos diferentes fatores que influenciam a inscrição das afetividades na linguagem.

Wierzbicka (1999), por exemplo, defende que o conceito de emoção é transcultural. As emoções humanas seriam diferentes no que se refere às suas expressões lingüísticas e em função dos extratos sócio-culturais a que estão ligadas, porém a cognição humana e a experiência são consideradas universais. Utilizando termos como desejo, ressentir, pensar, bom, mau para construir cenários típicos, supõe que, uma vez descrita uma situação, o que vai sentir um sujeito normal é tipicamente universalizado. Propõe uma metalinguagem semântica para as emoções que não depende de uma língua específica. O pressuposto é o de que, estudando os traços desse fenômeno na língua inglesa, pode-se definir o que é ele em outras línguas. Suas descrições pressupõem que termos como bom e mau têm sempre sentido único para cada sujeito independente de qual o seu contexto de vivências.

O primeiro problema das conceitualizações de Wierzbicka está no fato de apoiar-se em definições clássicas das emoções e, em segundo, porque são definições generalizantes que ignoram as especificidades de cada língua e, dentro desse universo, ignoram o que o sujeito pode fazer a partir do diálogo com sua própria cultura. O que é elidido é a diferença na forma de viver os acontecimentos e, como estes são constitutivos das vivências e cognições interiores, o sujeito pressuposto nesses estudos é homogêneo. A autora abandona o fato óbvio de que há relação entre as atividades lingüísticas e as atividades cognitivas; e o mais óbvio ainda, o de que as duas atividades não se dão fora de contextos reais de uso. 
Quanto à movimentação interna da língua, os estudos desenvolvidos por Anscombre (1995 e 2005), centrados na análise do léxico para definir os termos pertencentes ao campo subjetivo das emoções, apontam dificuldades para fazer delimitações dos adjetivos de afetos. Contrariamente ao que ocorre com os nomes, a classificação dos adjetivos não pode se basear na estrutura de funcionamento de argumentos porque não há relação biunívoca entre os nomes e os adjetivos e, quando em uso, destes com os predicados adjetivos. A derivação de substantivos para adjetivos é implodida pela dissimetria entre definições sobre o que seja uma pessoa triste, quando vinda de outrem, e eu estou triste, quando enunciada pelo sujeito experenciador. Anscombre, para fazer uma categorização dos nomes e adjetivos de emoções, conclui que é necessário trabalhar com a categorização macro: endógenos para os nomes de sentimentos (internos) e exógeno para os nomes de emoção (externas).

Entretanto, nesses casos, ocorrem redirecionamentos de sentidos que também desestabilizam a distinção, pois certos nomes apresentam características próprias as duas categorias, como é o caso de respeito: respeito tem a estrutura argumental de um nome endógeno quando define o respeito por alguém e tem a estrutura de um nome exógeno quando define o respeito diante da natureza. Como as preocupações de Ascombre se voltam para a distribuição de um campo axiomático para as classes gramaticais de nomes e adjetivos de emoção, ele trabalha com a lógica de que os sentidos afetivos estão colados a determinadas formas da língua. Isto é, estariam muito mais colados à língua que à enunciação. O problema surge porque tal perspectiva não se confirma tal e qual quando se consideram os traços de significações de um léxico retirado de diferentes situações de uso.

Os problemas que envolvem os estudos que tratam da relação entre emoções e linguagem estão ligados, por um lado, aos extremos criados pelas correntes teóricas que tratam a questão das emoções como pertencente exclusivamente ao mundo do sujeito ou da língua e, por outro lado, a persistência histórica de assentar as emoções como o desvio, o acessório e o contingente. Sobre as primeiras posições pode-se argumentar que os sentidos afetivos não se constroem somente pelo extraverbal porque isso seria ignorar a existência do léxico usado para referir-se às experiências emotivas e, principalmente, encerrar os sentidos afetivos no imenso universo das subjetividades individualizadas. $\mathrm{O}$ ato de nomear uma emoção pode ser uma simples estratégia para manipular. As declarações de amor nos dias atuais nem sempre remetem à emoção nomeada. Segundo Parret 
(1997), o termo transformou-se em um slogan. Porém, dada a finitude dos termos ligados a esse campo semântico, a mesma palavra "amor" ainda continua sendo necessária para quem quer fazer uma declaração ao ser amado. Ou seja, para compreensão desse fenômeno como parte integrante da linguagem, é necessário refutar as bases das duas posições dicotômicas e a possibilidade de pensar a estabilização de construções lingüísticas que signifiquem sem a intervenção do sujeito.

\section{ENUNCIAÇÃO E EMOÇÃO}

Bakhtin não trata diretamente sobre as formas de constituição da enunciação, mas suas idéias sobre a linguagem permitem derivar uma concepção de enunciação como centro de referência para construção dos sentidos dos fenômenos lingüísticos. A linguagem para este autor é sempre um evento, está sempre em (re)construção pelos atos praticados pelos sujeitos em situação de interação. $\mathrm{O}$ autor critica as concepções abstratas que consideram a linguagem como um sistema de normas, uma vez que, nas situações em que usa a linguagem, os sujeitos não a mobiliza como sistema. Tal sistema é apenas uma abstração. Contrapondo-se a isso, Bakhtin apresenta, sobretudo em Marxismo e Filosofia da Linguagem, um conjunto de reflexões sobre o que é a língua quando imersa na realidade enunciativa concreta, servindo aos objetivos comunicativos.

A palavra (termo equivalente, algumas vezes, à linguagem) em estado de dicionário nãoéuma realidade da qual o falante se vale para os seus propósitos comunicacionais. "Na realidade, não são palavras o que pronunciamos ou escutamos, mas verdades ou mentiras, coisas boas ou más, importantes ou triviais, agradáveis ou desagradáveis" (BAKHITIN, 1929, p.85). Todo ato de linguagem está impregnado de um conteúdo apreciativo. Os acentos emotivos-volitivos compõem a significação e são considerados pelos envolvidos nos atos de interlocução. A internalização da palavra do outro é também a internalização de valores, tons apreciativos. Por isso, pode-se dizer que Bakhtin concebe a enunciação como um produto da interação de sujeitos socialmente organizados mesmo quando o interlocutor ocupe uma posição mediata. A unidade da língua passa a ser, portanto, não o sistema abstrato, a unidade precisa, mas toda a comunicação verbal.

Os atos de linguagem, segundo Bakhtin, são compostos por elementos verbais e extraverbais, a saber: 1) "o horizonte espacial comum entre os interlocutores"; 2) "o conhecimento e a compreensão compartilhada entre os interlocutores de um determinado discurso"; 3) "a avaliação comum 
que fazem da situação em que se dá a produção do enunciado" (1926, p. 4). $\mathrm{O}$ autor defende que o diálogo entre o verbal e o extraverbal não pode ser reduzido a relações lógicas, lingüísticas, psicológicas ou naturais. São relações específicas, próprias dos acontecimentos de linguagem e, por isso, se estabelecem entre enunciados ou mesmo no interior dos enunciados. No interior dessa inter-relação, constroem-se os índices de valores, uma vez que não são meras interligações entre enunciados, e sim interações complexas entre sujeitos por meio da linguagem. Por essa concepção, as avaliações e julgamentos de valores são centrais na constituição dos sentidos. $\mathrm{O}$ tom e o valor elevam o ato de linguagem à condição de evento único.

No entrelaçamento entre verbal e extraverbal nascem os sentidos (para Vigotski o significado). Bakhtin diferencia tema e significação. Esta é a parte estável da língua, mas que por si só não responde pelos sentidos das enunciações. É a capacidade potencial de construir sentidos, algo próprio dos signos lingüísticos. O tema é o "sentido da enunciação completa", sendo único, não repetível. Nas situações concretas e vivenciais, aquele que fala serve-se da língua para suas necessidades enunciativas concretas e, por isso, o centro de gravidade, para ele, não está na conformação da norma ou na utilização de um recurso lingüístico específico, mas no novo sentido que cada forma pode adquirir no contexto da enunciação. O que importa para um interlocutor que está alegre ou triste necessariamente não é o uso de tais signos lingüísticos, mas aquilo que permite que as palavras usadas o figurativizem para seu interlocutor como um sujeito triste ou alegre. No mundo das práticas efetivas, não há separação entre as abstrações conceituais e o próprio ato vivido. Um constitui o outro e daí a dificuldade de estabelecer um grande espectro de termos lexicais e elementos ou torneios sintáticos que remetam ao universo das afetividades de modo abstrato e limpo.

Se considerarmos a perspectiva bakhtiniana, é difícil conceber os atos de linguagem como algo destituído da presença das emoções, pois o sujeito semantiza a língua no evento enunciativo. Esse evento, conforme veremos, é constitutivo da vida interior dos sujeitos. A língua, de fato, não se constitui separada dos eventos humanos e, exatamente por isso fica difícil continuar defendendo que o ato de fazer a linguagem significar nas interlocuções entre o eu e o outro é somente assegurado pelo rigor da razão, ou por certa formalização. A enunciação, tal como concebida aqui, implica que os sujeitos nascem e se movem dentro dos universos de linguagem. Tanto que, conforme Vigotski (1934), as faculdades superiores (que são genuinamente 
humanas), para se constituírem, são mediadas pela linguagem. A enunciação como condição para o funcionamento da linguagem, põe em cena um sujeito encarnado, com um corpo linguagem.

É possível que algumas das nossas ações físicas sobre o mundo das coisas possam ser desprovidas de emoção, ou mais sutilmente pode ser que a emoção tenha um peso apenas relativo para ações que realizamos no curso normal dos acontecimentos. Entretanto, é muito difícil supor que alguma coisa possa ser feita, a partir da linguagem, sem que a emoção seja um componente interveniente (MARI \& MENDES 2007, p. 154).

Pela concepção acima exposta, na enunciação também estão inseridas as emoções. Se os interlocutores agem no universo da linguagem a partir das interpretações, dos sentidos que constroem baseados em valores emotivovolitivos, não há como deixar de lado as emoções. Elas fazem parte da enunciação porque o corpo envolvido nos processos de interlocução é encarnado, sensível porque constituído sempre por meio de relações intersubjetivas. Conforme demonstrado em outro momento deste trabalho, o corpo tem sempre e necessariamente lugar na formação da linguagem. No diálogo entre o que é discurso interior e discurso exterior, que pode ser responsável por uma determinada entonação, o elemento primordial é a palavra. Nela ficam as marcas do corpo que também é constituído por meio das palavras alheias e próprias.

Em suma, as emoções não trazem para a linguagem um mero corpo biológico, mas um corpo-linguagem. É como tal que ele se faz presente nos processos enunciativos. Esse corpo, portanto, se movimenta respondendo às leis, pressões, controles vindos dos universos de linguagem. A enunciação traz para o enunciado as marcas do trabalho dos sujeitos e, por isso, não é possível pensar em interlocutores racionais, detentores de uma linguagem limpa e objetiva. Abrir-se para a enunciação implica ceder espaço para as vivencias, para vida como elemento constitutivo da linguagem.

\section{ASPECTOS TEÓRICOS PARA ANALISAR A EMOÇÃO POR MEIO DA E NA LINGUAGEM}

Um dos problemas que surge quando se fala em pôr as emoções como objeto de linguagem é o de saber como realizar as análises. Mesmo para os que assumem que esse fenômeno pode ser objeto de interesse dos estudos lingüístico-discursivos, permanecem nebulosas as discussões 
sobre quais procedimentos lingüísticos adotar para caracterizar a presença das emoções. A maioria dos trabalhos que discute esse tema volta-se para a necessidade de definir o aspecto lingüístico das emoções. Eggs (2000) assinala que todas as emoções, atitudes, os bons e maus hábitos, as manifestações feias e belas são lexicalizados e gramaticalizados em uma multiplicidade de palavras, torneios e construções enunciativas que surgem por meio de uma determinada forma de organização do discurso. Plantin (2003) complementa essa concepção ao defender que há uma estruturação do emotivo na língua cuja materialização é possível de ser identificada nas formas de organização do discurso.

Para analisar o discurso de emoção focalizando sua estruturação, Plantin (2003) propõe, com base na consideração de elementos lexicais, uma estrutura sintática para o que denomina enunciados de emoção. Este recebe a seguinte definição: "o enunciado de emoção atribui uma emoção a uma pessoa [seja ela o próprio locutor ou o interlocutor] e, em certos casos, menciona a fonte da emoção ${ }^{3 "}$ (p. 108). Pela conceitualização apresentada, a declaração "eu estou triste porque minha amiga partiu" pode ser caracterizada como enunciado de emoção porque apresenta um sujeito que enuncia sua tristeza (lugar psicológico marcado por um substantivo subjetivo) e localiza a fonte dessa emoção (a partida da amiga). Os três elementos identificadores são: quem fala (se é o sujeito ou não das emoções), o que fala e porque fala.

Plantin (2003) afirma ainda que existem os termos indiretos de emoção, derivados de enunciados que não comportam palavras que remetam diretamente ao campo semântico das emoções, mas que são suscetíveis de provocar e/ou conotar efeitos afetivos. Diante dessa possibilidade, surge o velho problema de que a localização dos enunciados com base em termos ou palavras pertencentes ou não ao universo semântico das emoções não implicará na afirmação de que, embora descreva uma emoção, o sujeito esteja emocionado ou então que o discurso produzirá efeitos de sentidos emotivos. Tendo por referência o que diz Ducrot (1984) sobre a orientação argumentativa, a orientação dos sentidos afetivos de um termo ou palavra pode mudar, quer seja para não produzir efeitos de emoção ou para produzir, de acordo com as orientações e objetivos do discurso.

\footnotetext{
3 "l'enoncé démotion attribue une émotion à une personne et, dans certains cas, mentionne la source de lémotion".
} 
Ora, diante dessa instabilidade, parece muito mais produtivo assumir que a estruturação dos termos e enunciados de emoção obedece aos direcionamentos e objetivos do discurso. Sua organização lingüística põe o enunciador no lugar de avaliador, pois, trabalhando com o que lhe é dado pelo campo do visível e pelo que é enunciado pelo outro, organiza o discurso envolvendo recursos verbais e extraverbais. Tal organização pode indicar solidariedade pela assunção da posição de empatia ou pode indicar rejeição, esta marcada, por exemplo, pela ironia. Por meio do trabalho com o lingüístico, os sujeitos se recolocam, excluem e incluem a si mesmos e ao interlocutor no jogo interlocutivo. A seleção de um elemento lingüístico e não de outro aponta para um trabalho não aleatório; ao contrário, é resultado das percepções avaliativo-afetivas, direcionadas ao objeto e/ou ao outro sujeito.

Assim, no que tange à dimensão lingüística, a língua constitutiva do das emoções é uma sistematização aberta (produto de determinações e indeterminações), formada com base nas "ações do sujeito sobre a linguagem". Esse trabalho é responsável por deslocamentos nos sistemas de referências da língua, produzindo com isso certa novidade não só em termos de sentidos afetivos como também em referência ao uso dos termos lingüísticos. Não há como falar na construção de um sistema que garanta a existência de um campo semântico específico das emoções. Os termos lingüísticos por si sós, nas condições de discurso, não garantem a construção dos sentidos, afetivos ou não, porque o uso da linguagem, o "falar depende não só de um saber prévio de recursos expressivos disponíveis mas de operações de construção de sentidos destas expressões no próprio momento da interlocução" (GERALDI, 1995, p. 9). O signo verbal que provoca emoções (ou as expressam) apresenta um potencial semântico próprio da língua, mas a consideração do contexto concreto, do acontecimento enunciativo de sua realização é fundamental a sua definição.

O caráter singular do acontecimento enunciativo se traduz num processo em que a (re)atualização dos sentidos ou de um signo lingüístico nas interações assume função primordial para qualquer estudo que se debruce sobre a constituição das emoções como elemento de linguagem pois, ainda segundo Geraldi, é a dinâmica do trabalho lingüístico que é relevante. A semântica de cunho emotivo é subversiva, escapa ao controle porque não está submetida a uma lógica racional interna, e sim ao que é próprio do sujeito. Não temos como construir compreensões acerca de 
como as emoções fazem parte da linguagem sem uma teoria da enunciação. Implica a leitura dos enunciados dentro de uma enunciação. Isso faz com que os sentidos extrapolem os limites dos enunciados lingüísticos. $\mathrm{E}$ bem entendido, a enunciação não é uma pitada de sentido a ser incorporada as significações estabilizadas de um determinado termo lingüístico. Aliás, Bakhtin (1929) rejeita tal dicotomia porque ela separa, impõe hierarquias naquilo que não está separado ou hierarquizado. Isto é, separa sentidos e signo lingüístico quando o signo é sempre pluriacentuado.

A enunciação é condição, acontecimento (ou um ato como quer Bakhtin) e efeito de sua existência (MARI \& MENDES 2007). Optar por uma análise das emoções na e por meio da linguagem considerando os processos enunciativos significa considerar a linguagem como acontecimento: algo que se organiza em torno da tensão criada sempre entre o locutor e o interlocutor e destes com a própria língua. $\mathrm{O}$ que nasce do encontro é acontecimento porque não é determinado pela rigidez do sistema nem pela soberania do sujeito. Aliás, a tensão nasce exatamente porque há indeterminação. O discurso é um espaço sem garantias rígidas e por isso é necessário o trabalho, o que obriga o sujeito a trabalhar com e sobre a linguagem para dar conta de um projeto de dizer.

Assumir esse postulado não significa defender que o plano do signo lingüístico não é relevante para compreender a relação entre linguagem e emoção, mas assumir que sua semântica não pode ser construída sem comportar necessariamente duas dimensões em estreita correlação: a significação dada pela estrutura (aquilo que é sempre igual) e os sentidos dados pela enunciação (aquilo que é mutável e/ou adaptável) - ou seja, é necessário assumir que o mesmo (o lingüístico) pode ser sempre outro (por isso, a palavra é signo por excelência) quando os sujeitos fazem uso da língua. Obviamente, isso traz intranqüilidade àqueles que estão acostumados a sempre apostar nas estabilidades dos sistemas com a finalidade de reter os sentidos dos enunciados como algo que pode ser rigorosamente recuperável. Porém, apostar nas instabilidades dos sentidos, não fechá-los em sistemas, no que tange ao discurso de emoção, pode ser uma alternativa para rompermos a oposição entre sentido e fato, entre o universal e o individual, entre a língua e a linguagem (GERALDI, FIHTNER, BENITES 2004). 


\section{A EMOÇÃO E LINGUAGEM NAS INTERAÇÕES EM SALA DE AULA ${ }^{4}$}

A seqüência discursiva ${ }^{5}$ analisada a seguir faz parte de uma aula de uma turma de segundo ano do Ensino Média (EM). Se no EF o aluno é gradativamente inserido no mundo das palavras ligadas aos saberes formalizados, mas ainda não é instado a falar sobre o que sabe sobre eles, no EM deparase com a necessidade de manuseá-las para dizer sobre o que entendeu, dar opinião sobre o que leu e atestar que aprendeu. É o momento em que se vê obrigado a sustentar a posição de quem diz "eu penso", "eu entendo". Tais exigências o colocam diretamente em confronto com as possibilidades e impossibilidades que marcam a construção do dizer. Nos diálogos, emerge certa tensão entre o compreender e o falar sobre o que foi feito da leitura de determinado texto porque existem regras que atestam a capacidade do sujeito de manusear a linguagem ligada aos saberes formais. Por isso, o ato de enunciar é marcado por auto-avaliações que, baseadas em valores e saberes partilhados entre os interlocutores, definem a continuidade, os cortes e retomadas do e no discurso.

Assim, como a entrada no universo dos saberes formais constrói-se sempre na presença do olhar mensurador do professor e dos demais alunos, o aprendizado sobre como sustentar a posição de sujeito de saber faz surgir enunciados que marcam os sentimentos nascidos em razão de tal luta. A dificuldade que faz silenciar, expressar ou enunciar uma emoção resulta do fato que, postos no interior de saberes diciplinarizados, não basta ao aluno saiba de sua existência, é necessário que aprenda a produzir comentários opinativos sobre eles. Na seqüência seguinte, os conflitos fazem surgir o

\footnotetext{
${ }^{4} \mathrm{O}$ corpus analisado neste artigo faz parte de uma pesquisa maior e que foi constituída por aulas do Ensino Fundamental, Médio e da Universidade. As gravações foram realizadas no decorrer do ano de 2004, para compor o corpus de minha tese de doutorado, em duas escolas públicas de Ensino Médio, localizadas nos Municípios de Santa Bárbara do Oeste e Campinas; duas Escolas de Ensino Fundamental, também públicas, localizadas no Município de Campinas, e em uma Universidade Pública, localizada na cidade de São Paulo.

${ }^{5} \mathrm{O}$ termo "seqüência discursiva", segundo Plantin (2003), assinala que as análises não serão realizadas com base em pequenos fragmentos, mas considerando o todo das situações de interação verbal que envolve um acontecimento em sala de aula. O leitor verá que serão mobilizadas longas seqüências com o objetivo de contextualizar um pequeno indício lingüístico-discursivo. Ressalta-se ainda que as seqüências discursivas e as partes que dela foram destacadas, no corpo do artigo, estão transcritas em fonte courier new. Essa diferenciação tem o objetivo de marcar a presença do outro, da diferença que significa para que o meu texto se constitua.
} 
aluno como um sujeito que se emociona e o professor como um sujeito que discursiviza as emoções visando construir uma situação de interação em torno do objeto de ensino:

\begin{tabular}{|c|c|c|}
\hline & \multicolumn{2}{|c|}{ A2 $^{\text {AEM }^{6}}$} \\
\hline & & {$[\ldots]$} \\
\hline 01 & $\mathrm{P}$ & (..) pessoal/ hoje vamos falar do texto da \\
\hline 02 & & clarice lispector (.) todos lembram que era pra \\
\hline 03 & & ler o conto felicidade clandestina// eu deixei no \\
\hline 04 & & xerox pra vocês fazerem cópia (..) é::h todo mundo \\
\hline 05 & & $\mathrm{fez} / /$ \\
\hline 05 & AA & fize:::mos/ \\
\hline 06 & $\mathbf{P}$ & esse é um texto muito legal né/ a clarice é \\
\hline 07 & & maravilho::sa (...) sou apaixonada por ela $\backslash()$. \\
\hline 08 & & todo mundo leu o texto// \\
\hline 09 & AA & eu li/ ((várias vozes ao mesmo tempo)) \\
\hline 10 & $\mathrm{P}$ & (...) acho que temos leituras suficientes para \\
\hline 11 & & fazermos a discussão (..) quem não está com o \\
\hline 12 & & texto senta do lado do colega que tem (.) isso não \\
\hline 13 & & vai resolver o problema mas dá pelo pelo menos \\
\hline 14 & & para acompanhar a aula (...) eu gostaria que vocês \\
\hline 15 & & fizessem um círculo assim fica melhor pra nossa \\
\hline 16 & & conversa (..) vamos lá// \\
\hline 17 & AA & ((várias conversas enquanto arrumam as mesas)) \\
\hline 18 & $\mathrm{P}$ & oke::i/ podemos começar né/ primeiro gostaria de \\
\hline 19 & & saber o que vocês acharam do texto// \\
\hline 20 & A1 & difícil (.) não en[tendi nada p’ofessora \\
\hline 21 & A2 & [eu gostei professora/// \\
\hline 22 & A1 & eu fiquei cansado e dormi quando estava lendo/= \\
\hline 23 & A3 & =ele é preguiçoso professora/ só é esperto quando \\
\hline 24 & & lê revista de sexo/ \\
\hline 25 & $\mathrm{P}$ & tá/ não vamos revelar as intimidades dos colegas \\
\hline 26 & & aqui(.) alguém pode começar fazendo um resumo d \\
\hline 27 & & história// (...) \\
\hline 28 & A2 & professora/ o conto fala da história de uma menina \\
\hline 29 & & que queria pegar um livro emprestado (..) a dona \\
\hline
\end{tabular}

\footnotetext{
${ }^{6}$ A2AEM significa: aula de segundo ano do ensino médio; $\mathrm{P}$ significa: professora; AA significam vários alunos; $\mathrm{A} 1, \mathrm{~A} 2, \mathrm{~A} 3$ marcam a tomada do turno de fala por diferentes alunos.
} 


\begin{tabular}{|c|c|c|}
\hline 30 & & do livro era um menina gorda baixa (..) por isso \\
\hline 31 & & ela não gostava das colegas porque elas eram \\
\hline 32 & & magras (...) é::: o pai da menina gorda tinha uma \\
\hline 33 & & livraria (..) ela:: tinh $=$ \\
\hline 34 & A5 & $=$ ela não queria emprestar um livro pra colega que \\
\hline 35 & & queria muito o livro das reinações de narizinho \\
\hline 36 & & (.) a menina gorda era mesquinha professora/ \\
\hline 37 & $\mathrm{P}$ & sim \vocês sabem porque o título conto felicidade \\
\hline 38 & & clandestina// quem pode falar sobre isso// \\
\hline 39 & A4 & a::h professora é porque fala da felicidade da \\
\hline 40 & & menina quando conseguiu pegar o livro que queria \\
\hline 41 & $\mathrm{P}$ & isso é parte mas tem mais coisa aí/ (..) G/ você \\
\hline 42 & & sabe porque o título do conto// em que momento a \\
\hline 43 & & clarice lispector explica o motivo da felicidade \\
\hline 44 & & clandestina da personagem//(inaudível) \\
\hline 45 & A6 & professora/ acho que é porque ela gostava de ler \\
\hline 46 & & (..)ela diz que o livro era como aman- a::h eu \\
\hline 47 & & não consigo explicar direito professora $/=$ \\
\hline 48 & $\mathrm{P}$ & mas você pode continuar/ o livro era como amante/ \\
\hline 49 & & porque// o que aconteceu pra ela dizer isso// a \\
\hline 50 & & felicidade dela era porque tinha enfim \\
\hline 41 & & conseguido pegar o livro da outra// vai lá G/ eu \\
\hline 52 & & sei que você leu (.) só está com vergonha(.)não \\
\hline 54 & & precisa se preocupar se vai falar direito ou não/ \\
\hline 55 & & (..) ou vocềs acham que eu e a $M$ também não temos \\
\hline 56 & & os mesmos problemas (..)também sentimos vergonha \\
\hline 57 & & de falar pros nossos professores/ \\
\hline 58 & A7 & mas é diferente né professora/ vocês já são \\
\hline 59 & & professoras \\
\hline 60 & $\mathrm{P}$ & só por isso você acha que não sentimos vergonha(.) \\
\hline 61 & & $\begin{array}{l}\text { insegurança também// } \\
{[\ldots]}\end{array}$ \\
\hline
\end{tabular}

A seqüência apresenta dois indícios de relação entre emoção e linguagem. São eles: a) a professora que enuncia sua relação com a obra de Clarice Lispector; b) a aluna que tenta e em seguida se recusa a responder às perguntas sobre a razão do título do conto. No caso da professora, há a discursivização das emoções. Já no caso da aluna, temos um movimento com a linguagem em que denota uma situação de emoção. Para dar início à aula, a professora (linhas 06 e 07) enuncia sua paixão (o que pode ser traduzido em: gosto muito, amo) e vivência prazerosa de leitura. E para 
justificar porque se realiza como tal, Clarice Lispector é descrita como maravilhosa. Declarar-se apaixonada pela autora é um recurso para explicitar o sentimento causado pela leitura. Em termos de efeito de sentidos, o relato do que sente em relação ao texto e a autora coloca professores e alunos na posição de quem podem compartilhar, de modo liberto, opiniões sobre o conteúdo. Em termos de ensino, o mesmo enunciado estabelece direcionamentos para olhar o texto, pois, pela opinião subjetiva afetiva, impulsiona o aluno a avaliar o conto com base nas paixões produzidas na professora como leitora.

Para Wallon (1968), são os aspectos afetivos que movem a construção do conhecimento, uma vez que são os motivos, desejos e necessidades do sujeito que o fazem mover-se em direção à construção de saber. O desejo nasceria do estabelecimento da idéia que o discurso da professora é sincero. Por tal perspectiva, pode-se dizer que, apostando na sua relação afetiva com os alunos, põe-se como fiadora da relação destes com a leitura. A enunciação da opinião (que antecede a apresentação formal do objeto de conhecimento) busca estabelecer um tipo de laço em que o aluno se veja impelido também a viver o mesmo sentimento de prazer (porque o texto é legal) e paixão. Ou seja, a discursivização do afetivo busca despertar o interesse, a adesão à obra por meio do reconhecimento de identificações de reações e comunhão de sensibilidades.

Por essa perspectiva, a o relato dos estados interiores funciona como meio de apresentar ao aluno o mundo simbólico da cultura, tanto que os afetos estão direcionados ao objeto de conhecimento e não aos interlocutores. E aqui o objetivo não é somente a realização da leitura que está em questão, trata-se também de levá-los a construir uma relação consigo mesmos pela ancoragem na crença de que são sujeitos que podem atingir certo tipo de felicidade (valorada pelos espaços sociais mais amplos) porque se dispuseram a se inserirem no mundo do saber. Em suma, a professora põe-se como um sujeito de emoção descrevendo a sua paixão pela leitura, porém não é possível questionar a veracidade desse enunciado. É pela idéia, construída por meio da linguagem, de que o relato de si é uma exposição "verdadeira" e "sincera" dos aspectos afetivos que instiga (ou não!) os alunos a estabelecerem a mesma relação com a leitura.

O gesto enunciativo da professora pode ser caracterizado como um ato linguageiro que descreve seu estado interior. E esse estado é pressuposto pela própria enunciação. Nesse sentido, pode-se dizer que o sujeito que enuncia eu estou triste impõe uma terminada intensidade, uma entonação 
emotiva que garante a condição de verdade do enunciado. Os atos que descrevem emoção carregam efeitos de sentidos ligados à intenção com que esse ato foi produzido. Nesse caso, ao mesmo tempo, catalisam e anunciam a existência de um estado emotivo. Obviamente, esses exemplos demonstram a necessidade de prever uma patemização nas trocas verbais cotidianas, ligada ao prazer e desprazer das interações entre interlocutores. $\mathrm{Na}$ sala de aula, por exemplo, a todo o momento, surgem oportunidades de ganhos e perdas e de prazer e desprazer e com elas o sentimento de interesse, de se fazer compreender, de partilhar valores, concepções, de ser reconhecido, aceito pelo outro. Esses pequenos acontecimentos fazem surgir uma emoção que, essencialmente, depende da linguagem para existir, pois não está ligado a um acontecimento provocador de grande emoção, tal como a morte de um ente querido, por exemplo.

$\mathrm{Na}$ segunda situação, a aluna, ao tentar responder a pergunta da professora, faz um corte no seu enunciado: professora/ acho que é porque ela gostava de ler (..)ela diz que o livro era como aman- a::h eu não consigo explicar direito professora/=. A metáfora do livro como amante, a meu ver, justifica a afirmação de que sabe, mas não consegue explicar. O não-saber não remete à incompreensão do que leu, mas à dificuldade de abordar um tema que aparentemente está ligado ao corpo como artefato biológico e não intelectualizado. Corrobora para essa hipótese o corte abruto que faz no enunciado ela diz que o livro era como aman-. O corte, embora somente de um elemento morfológico, parece ter o objetivo de ir contra o próprio discurso, avaliando-o, desqualificando-o e, por fim, bloqueando a sua continuidade.

A palavra amante remete a discursos ligados ao campo da sexualidade, o que, a meu ver, provoca o sentimento de vergonha, cuja materialidade se faz pela interrupção abrupta do projeto de dizer. O corpo humano, sabemos, "não existe como um artigo biológico ou como material. O corpo existe no interior e através de um sistema político. $O$ poder político dá um certo espaço ao indivíduo: um espaço onde se comportar, onde adaptar uma postura particular, onde sentar de uma certa maneira, ou trabalhar continuamente" (FOUCAULT, 1970, p.259). O conhecimento desses diferentes modos de ser ocorre pela escritura e encarnação, no corpo, de saberes. É a memória de sentidos que a palavra retoma que provoca na aluna o sentimento de vergonha.

Com o que diz Foucault, tocamos nas questões ligadas a questão da subjetivação. Esta é o produto de saberes e técnicas que circunscrevem os seres humanos em espaços de visibilidades a partir da atribuição de certas 
características de posições, de modos de ser e de dizer. As produções externas, inscritas no corpo, formam o forro de sustentação das relações consigo mesmo e com o outro pela instauração de uma série de procedimentos de individualização, de definições e controles sobre a conduta humana. Esse processo atinge a vida cotidiana nas suas formas mais ínfimas (constitui a vida interior), uma vez que o "eu", na forma mais íntima, por não ser exterior nem anterior à linguagem, constrói, vive e define, para si e para o outro, as suas experiências políticas emocionais, culturais e sociais com base nas regras de saber e poder que marcam o seu tempo. Nesse sentido, a vergonha expressada pelo corte no enunciado se dá porque a palavra amante remete aos valores que definem o discurso sobre o segredo, sobre a decência que recobrem o tema.

Porque a vida interior se forma nas relações intersubjetivas, a palavra ganha a possibilidade de tocar, gerar emoções. O discurso do professor que se diz apaixonado pela literatura pode não produzir no aluno uma emoção imediata, mas o modo como cada professor se relaciona com os objetos de conhecimento é constitutivo da relação que o aluno estabelecerá (ou não) com esse mesmo objeto. Tanto para Bakhtin (1929), como para Vigotski (1934), os sujeitos se constituem interiormente por meio da linguagem. A vida interna é sócio-ideológica, construída por signos: prioritariamente pela palavra, definida como signo ideológico por excelência. É pela internalização de signos que o corpo, sem deixar sua composição física, passa a ser corpo social, corpo inserido no mundo da cultura. Ou melhor, ao ser inserido no mundo da cultura, e isso ocorre no instante mesmo do nascimento, os signos e valores sociais passam a organizar as funções típicas do organismo humano, dando-lhe formas de se alimentar, de se comunicar, de sentir e experienciar os acontecimentos. Nesse emaranhado, nasce um eu habitado pelo outro, uma vez que este chega sempre na forma de palavra carregada de tons emotivo-valorativo.

\section{CONCLUSÃO}

Ao longo desde texto, busquei demonstrar que um estudo das emoções, para ter um lugar nos estudos da linguagem do século XXI, precisa ter como objeto a linguagem que significa nas situações de interação entre interlocutores. Essa linguagem é signo de qualquer coisa que não existe como materialidade concreta, mas que é constituidora desse signo afetivo. A tristeza, a alegria, a irritação, a cólera não podem ser consideradas pelo 
modo como o sujeito as manifesta em seu psiquismo, muito menos como uma categoria que se põe de acordo com o que é uma pessoa (nervosa, irritada), ou segundo a situação em que se encontra (quando se encontra diante do perigo). Muito menos podem ser analisados como o sintoma de um comportamento coletivo. O discurso carregado de sentido de emoção é um signo do que pode ocorrer ao sujeito que pode enunciar "eu tenho medo", "eu estou alegre ou triste". Isso que é enunciado e que não está somente no lingüístico, que não é essência denotativa que faria do tematizado na linguagem uma realidade transparente, contribui para construir a materialidade dos sentidos de emoção.

Portanto, a emoção, o juízo de valor, a expressão são estranhas à palavra da língua e surgem unicamente no processo do seu emprego vivo em um enunciado concreto. Em si mesmo, o significado de uma palavra (sem referência à realidade concreta), é extra-emocional. Há palavras que significam especialmente emoções, juízos de valor: "alegria", "sofrimento", "belo", "alegre", "triste", etc. Mas também esses significados são igualmente neutros como todos os demais. O colorido expressivo só se obtém no enunciado, e esse colorido independe do significado de tais palavras, isoladamente tomado de forma abstrata; por exemplo: "Neste momento, qualquer alegria é apenas amargura para mim" aqui "alegria" recebe entonação expressiva, por assim dizer, a despeito do seu significado. [...] Quando escolhemos as palavras no processo de construção de um enunciado, nem de longe as tomamos sempre do sistema da língua em sua forma neutra, lexicográfica. Costumamos tirá-las de outros enunciados e antes de tudo de enunciados congêneres com o nosso, isto é, pelo tema, pela composição, pelo estilo; consequentemente, selecionamos as palavras segundo a sua especificação de gênero. (BAKHTIN 1979, p. 292).

A linguagem que expressa e produz emoção sustenta-se nas trocas que fazem sentidos entre sujeitos situados em um contexto específico: os pontos de vista, os desejos e as intenções resultantes das vivências partilhadas ou não. Conseqüentemente, trata-se de um ato em que tanto o locutor como o interlocutor sustentam certa consciência das ações que praticam ou sofrem. Essa intencionalidade não nasce de uma individualidade auto-centrada, mas da liberdade que o sujeito tem, por ser constituído no universo da linguagem, de se figurativizar no próprio discurso a propósito de um acontecimento que o atinge. As emoções discursivizadas ou pressupostas não são a expressão direta de uma pulsação corporal, mas já a ressignificaçãoexposição da experiência vivenciada. 
Nas situações de interação analisadas, os sentidos de cunho emotivo surgem porque há um gesto de tomar ciência, de se dar conta de certas entonações, significações vindas dos interlocutores. Ea reflexão que antecede e resulta da consciência do que acontece (sentido de acontecimento) sustenta-se em um conjunto complexo de atos praticados pelos envolvidos no jogo discursivo. Depende, sobretudo, dos saberes, valores e crenças que os sujeitos carregam consigo em razão de sua história. As emoções nas interações em sala de aula nascem muito mais das interpretações feitas no contexto de produção do discurso.

Tanto na interpretação dos acontecimentos linguageiros vindos dos interlocutores como para se pôr a si mesmo como sujeito de uma emoção, ocorre o trabalho com os signos e semioses sociais. Estes são constituidores de nossos afetos e perceptos. E por se tratar de um discurso que remete o gera emoções, não são signos-enunciados isolados, mas que significam os acontecimentos, ao mesmo tempo que são acontecimentos e gestos de estar no mundo. Nas salas de aulas, os signos sociais servem para criar uma espécie de rede agrupadora de um vasto imaginário discursivo sobre o que seja aprender e ensinar, pois funcionam como indícios-sintomas que, carregados de valores passam a sustentar a construção dos modos de sentir, ver, agir e posicionar-se diante dos interlocutores e objetos de conhecimento. É um discurso que nasce do imbricamento entre a escuta e o dizer.

Diante disso, um estudo sobre a relação entre emoção e linguagem põe de modo incontestável a necessidade de considerar o papel da alteridade na construção do eu, uma vez que o "ser" se produz na intersecção com aquilo que não é. E não se trata de pensar somente em um movimento positivo de plena aceitação; ao contrário, inclusão e exclusão sustentam a construção do sujeito humano: é por essa via que o discurso de emoção ganha também o objetivo de ser um recurso de controle e delimitação dos movimentos discursivos vindos dos interlocutores. Isso faz da linguagem afetiva não um momento de encontros camaradas entre sujeitos, mas lugar das tensões entre diferenças de lugares e de desejos. Os atos de emoções e os atos de expressar emoção atestam a impossibilidade de ações unas e, nesse sentido, demonstra que o sujeito percorre um caminho muito específico para construir suas compreensões já que mobiliza saberes vindos do plano racional e sensível. Isso nos obriga a pôr o discurso de emoção não só como um ato irrevogável, que nunca pode ser o mesmo pela repetição, mas também como um ato praticado por um sujeito encarnado e situado. 


\section{REFERÊNCIAS BIBLIOGRÁFICAS}

AMOSSY, R. Largumentation dans le discours. Paris : Armand Colin, 2006.

ANSCOMBRE, J.C. Temps, aspect et agentivité dans le domaine des adjectifs psychologiques. Lidil, n. 32 : pp. 145-165, 2005.

Morfologie et représentation evenementielle: le cas des noms de sentiments et d'attitude. Langue française, n.105: pp. 40-45, 1995.

BAKHTIN, M.(1979). Estética da criação Verbal. Trad. Paulo Bezerra. São Paulo: Martins Fontes, 2003.

. (1929) Marxismo e filosofia da linguagem. Trad. Michel Lahud \& Yara Frateschi Vieira. São Paulo: Hucitec, 1995.

Discurso na vida e discurso na arte (1926). Trad. Inédita de Cristovão Tezza do artigo "Discourse in Life and Discourse in Art", publicado como apêndice in: Voloshinov, V.N. Freudianism: a marxist critique. New York: Academic Press, 1976.

BALLY, CH. (1913). Le language e la vie.Genève : Droz, 1935.

CHARAUDEAU, P. Une problématisation discursive de lémotion". In PLANTIN, C.; DOURY, M. ; TRAVERSSO, V (Org.). Les émotions dans les interactions. Lyon : PUF, 2000.

DUCROT, O. Le dire et le dit. Paris : Editions Minuit, 1984.

EGGS, E. Logos, ethos, pathos: l'actualité de la rhétorique dês passions chez Aristote. In PLANTIN, C.; DOURY, M. ; TRAVERSSO, V (Org.). Les émotions dans les interactions. Lyon : PUF, 2000.

FOUCAULT, M. (1970). A ordem do discurso. Trad. Laura Fraga de Almeida Sampaio. São Paulo: Edições Loyola, 1996.

GERALDI, J. W. Portos de passagem. São Paulo: Martins Fontes, 1995.

GERALDI, J. W.; BERNARD, F.; BENITES, M. Transgressões convergentes: Vigotski, Bakhtin e Bateson. Campinas: Mercado de Letras, 2007. 
JAKOBSON. R. (1923). Lingüística e comunicação. 20a Ed. Trad. Izidoro Blikstein e José Paulo Paes. São Paulo: Cultrix, 1992.

KERBRAT-ORECCHIONI C. Quelle place pour les emotions dans la linguistique du $\mathrm{XX}^{\mathrm{e}}$ siècle?. In Les emotions dans les interactions. Paris, 2000.

MARI, H. \& MENDES, P. H. Enunciação e emoção. In: As emoções no discurso. Rio de Janeiro : Lucerna, 2007.

PARRET, H. O pathos razoável. Trad. Roberta Pires de Oliveira. In: A estética da comunicação: além da pragmática. Campinas: Ed. Da Unicamp, 1997.

PLANTIN, C., Structures verbales de l'émotion parlée et de laparole émue. In Les émotions : cognition, languege et developpement. Paris : Mardaga, 2003.

SAPIR. E (1921). A linguagem: introdução ao estudo da fala. Trad. J. Matoso Câmara Jr. São Paulo: Ed. perspectiva, 1980.

SAUSSURE, F. de (1916). Curso de lingüística geral. $4^{\mathrm{a}}$ ed. Trad. Antônio Chelini, José Paulo Paes e Izidoro Blikstein. São Paulo: Cultrix, 1972.

VIGOTSKI, L, S. (1934) A construção do pensamento e da linguagem. Trad. Paulo Bezerra. São Paulo: Martins Fontes, 2001.

WALLON, H. (1968). As origens do caráter da criança. São Paulo: Nova Alexandria, 1995.

WIERZBICKA, A. Semantics. Primes and Universals. Oxford: Oxfords Univ. Press, 1999. 
